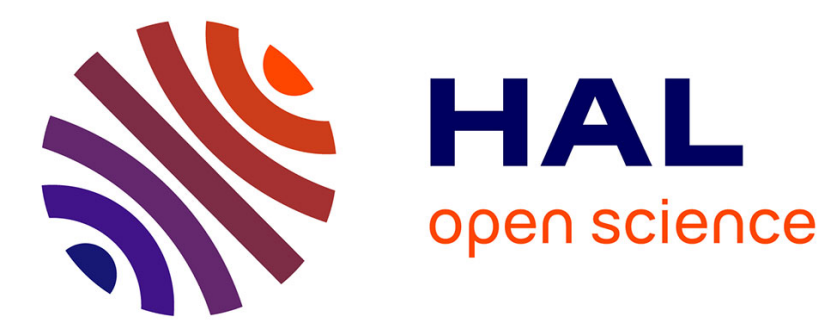

\title{
An integrated decision support system for global manufacturing co-ordination in the automotive industry
}

Shaofeng Liu, R I M Young, Lian Ding

\section{To cite this version:}

Shaofeng Liu, R I M Young, Lian Ding. An integrated decision support system for global manufacturing co-ordination in the automotive industry. International Journal of Computer Integrated Manufacturing, 2011, 24 (04), pp.285-301. 10.1080/0951192X.2011.554869 . hal-00681218

\section{HAL Id: hal-00681218 https://hal.science/hal-00681218}

Submitted on 21 Mar 2012

HAL is a multi-disciplinary open access archive for the deposit and dissemination of scientific research documents, whether they are published or not. The documents may come from teaching and research institutions in France or abroad, or from public or private research centers.
L'archive ouverte pluridisciplinaire HAL, est destinée au dépôt et à la diffusion de documents scientifiques de niveau recherche, publiés ou non, émanant des établissements d'enseignement et de recherche français ou étrangers, des laboratoires publics ou privés. 


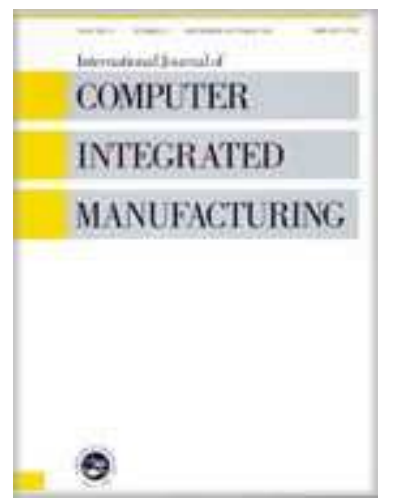

\section{An integrated decision support system for global manufacturing co-ordination in the automotive industry}

\begin{tabular}{|r|l|}
\hline Journal: & International Journal of Computer Integrated Manufacturing \\
\hline Manuscript ID: & TCIM-2010-IJCIM-0042.R2 \\
\hline Manuscript Type: & Original Manuscript \\
\hline Author: & 05-Jan-2011 \\
\hline Kemplete List of Authors: & $\begin{array}{l}\text { Liu, Shaofeng; University of Plymouth, School of Management } \\
\text { Young, R I M; Loughborough University, Wolfson School of Mech \& } \\
\text { Man Engineering } \\
\text { Ding, Lian; University of Bath, Mechanical Engineering }\end{array}$ \\
\hline Keywords (user): & $\begin{array}{l}\text { GLOBAL MANUFACTURING, DECISION SUPPORT SYSTEMS, MULTI- } \\
\text { CRITERIA DECISION MAKING }\end{array}$ \\
\hline \multicolumn{2}{|l}{ CO-ORDINATION } \\
\hline
\end{tabular}

\section{SCHOLARONE" Manuscripts}


An integrated decision support system for global manufacturing co-ordination in the automotive industry

\author{
S. Liu' ${ }^{1}$, R.I.M Young ${ }^{2}$ and L. Ding ${ }^{3}$ \\ ${ }^{1}$ Corresponding author: \\ School of Management, University of Plymouth, \\ Plymouth, Devon, UK, PL4 8AA \\ Tel: 01752585721 \\ Fax: 01752585713 \\ Email: shaofeng.liu@plymouth.ac.uk \\ ${ }^{2}$ Wolfson School of Mechanical and Manufacturing Engineering, \\ Loughborough University, Loughborough, UK, LE11 3TU \\ Tel: 01509227662 \\ Email: r.i.young@lboro.ac.uk \\ ${ }^{3}$ Department of Mechanical Engineering, \\ University of Bath, Bath, UK, BA2 7AY \\ Tel: 01225386131 \\ Email: Id218@bath.ac.uk
}


An integrated decision support system for global manufacturing co-ordination in the automotive industry

S. Liu' ${ }^{1}$, R.I.M Young ${ }^{2}$ and L. Ding ${ }^{3}$

${ }^{1}$ Corresponding author:

School of Management, University of Plymouth,

Plymouth, Devon, UK, PL4 8AA

Tel: 01752585721

Fax: 01752585713

Email: shaofeng.liu@plymouth.ac.uk

${ }^{2}$ Wolfson School of Mechanical and Manufacturing Engineering, Loughborough University, Loughborough, UK, LE11 3TU

Tel: 01509227662

Email: r.i.young@lboro.ac.uk

${ }^{3}$ Department of Mechanical Engineering,

University of Bath, Bath, UK, BA2 7AY

Tel: 01225386131

Email: Id218@bath.ac.uk 


\section{Abstract}

Global manufacturing increasingly faces decision challenges of how to better manage the dependencies between different activities that take place either locally or across different locations. Co-ordination decision making not only requires the right information to be provided in the right place at the right time, but also requires the right level of support from models for decision analysis and decision evaluation. Furthermore, the alignment of coordination decisions with a global firm's global environment and its operations performance has been identified as crucial to the firm's success, but remains a challenge to decision makers. This paper proposes an integrated decision support system (IDSS) that can facilitate manufacturing managers to make more efficient and effective global co-ordination decisions. A combination of qualitative and quantitative analysis and assessment functions has been provided through the system's four key components (a Global Context Modeller, a Multi-Criteria Scoring Modeller, a Configurator and a Co-ordinator). The evaluation of the decision system has been undertaken through a case study within the automotive industry, which demonstrates the applicability of the system to providing decision support for realistic global manufacturing co-ordination problems.

\section{Keywords}

Global manufacturing context, dependency and co-ordination, integrated decision support, multi-criteria decision making

\section{Introduction}

Over the last three decades, along with the phenomenon of globalisation, manufacturing management has been experiencing a paradigm shift from local through international to global level (Meixell and Gargeya, 2005). This paradigm shift has triggered many industries to innovate the ways they deliver their products through globally networked production systems. A direct consequence to the automotive industry is a fundamental change to their organisational structure. Specifically, it caused the recent emergence of a new structure and configuration of manufacturing networks (Trappey et al, 2007). Traditionally, manufacturing networks were organised in tiers (Mondragon and Lynos, 2008; Veloso and Kumar, 2002). For example, Original Equipment Manufacturers (OEMs) would design and assemble the cars. First tiers in the manufacturing network would manufacture and supply components directly to the automaker (e.g. the fuel pump). Second tiers would produce some of the simpler individual parts that would be included in a component manufactured by a first tier (e.g. the housing of the fuel pump), and third and fourth tiers would mostly supply raw materials. This relatively simple configuration required less co-ordination effort across the manufacturing network, because the majority of the interactions and communications only happened between the two consecutive tiers. However, this simple configuration no longer fits the actual structure of the industry in today's globalisation environment (Doran et al, 2007). The new direct suppliers are becoming large global firms, which are either specialised in complex systems, or integrators of a series of subsystems. Studies within the International Motor Vehicle Program and other outside analysts suggest that the new configuration involves a division (based on roles and responsibilities) along the following four lines (Veloso and Kumar, 2002):

- Systems Integrator: company capable of designing and integrating systems, subassemblies, and components into modules that are shipped or placed directly by the suppliers in the automakers' assembly plants.
Deleted: and between geographical locations

\begin{tabular}{l} 
Deleted: A particular important \\
outcome of this paradigm shift \\
\hline Deleted: in \\
\hline Deleted: the \\
Deleted: change \\
Deleted: the
\end{tabular}

Deleted: immediate 
- Global Standardiser - Systems Manufacturer: company that sets the standard on a global basis for a system and components. These firms are capable of design, development, and manufacturing of complex systems. Systems Manufacturers may supply motor vehicle manufacturers directly or indirectly through Systems Integrators.

- Component Specialist: a company that designs and manufactures a specific component or subsystem for a given car or platform. These firms will increasingly work as suppliers to Systems Integrators and Global Standardisers.

- Raw Material Supplier: a company that supplies raw materials to the OEMs or their suppliers. Some of the raw material suppliers are also moving into Component Specialists to add value to their products.

With the new configuration of global manufacturing networks, global firms are forced to take a substantial responsibility in the design and engineering of the systems, and more importantly in co-ordinating the networks for their manufacturing, assembly, and services (Nunes et al, 2005). Figure 1 illustrates the increasing complexity of interacting relationships that can be identified in the new flattened structure of global manufacturing networks. Therefore, in the new flat structure, the co-ordination requirements have been raised to a higher level (EIMaraghy and Mahmoudi, 2009). It has been acknowledged that the ultimate success of operations in global manufacturing enterprises depends on the companies' capability of co-ordination, synchronisation and integration of business activities (Weston and Cui, 2008).

Global manufacturing co-ordination has been proven challenging because of the overarching issues confronting global manufacturing, namely its dynamics, complexity, uncertainty, and high risk (Pontrandolfo and Okagbaa, 1999; Rudberg and West, 2008).

The dynamics of global manufacturing exist in many respects. These include the unbundling of different stages of the production process across the globe, the growing capacity for firms to outsource internationally, greater product differentiation, and the growth of the phenomenon of 'global value chain', whereby different businesses add value by different processes or activities at each stage of production (Nagurney and Matsypura, 2005; Needle, 2005; Slack et al, 2010). Accordingly, the traditional production model where firms were responsible for all stages of the production process of a particular product has changed. Many manufacturers now choose to specialise on particular steps in the production process, such as design, research and development, or sales and marketing, either within individual geographic locations or through participation in the global value chain, or through utilising outsourcing possibilities (Dreyer et al, 2009).

The complexity of global manufacturing can be understood from two dimensions. First, there is a complex network of inter-relationships between different activities. Second, these activities take place in a set of contexts including the strategic (e.g. management and leadership style, business ethics), organisational (e.g. structure, ownership and size) and environmental (e.g. economy, the state, culture difference) contexts (Needle, 2005). There are complex interactions between the activities and the context where they take place (Kazmer and Roser, 2008). Furthermore, it is also believed that the relationship between the

Deleted: In this respect

Deleted: by

Deleted: the sort of stylised

Deleted: the 
global manufacturing activities and the contexts is not static but dynamic (Liu and Young, 2004; Meixell and Gargeya, 2005).

Uncertainty of global manufacturing has been well acknowledged from the supply chain perspective, i.e. uncertainty from both demand and supply side (Kazmer and Roser, 2008). For example, Verdouw et al (2010) explored how to master demand and supply uncertainty with combined product and process configuration. Exchange-rate uncertainty and its impact on price setting are discussed in (Kazaz et al, 2005). In (Acar et al, 2010) the relative impact of three sources of uncertainties (supply, demand, and lead-time uncertainties) on cost and service performance is studied using mathematical models. Furthermore, factors such as regional, national and international economic (e.g. inflation, recession) and political instability, as well as the regulatory environment can raise extra challenges to the global manufacturing co-ordination.

Depending on the modes of entry, there are various degrees of risk in relation to global manufacturing. Among the six common modes of entry, exporting, licensing and franchising are considered as relatively low risk, while wholly-owned subsidiary (also known as FDI), international joint venture and off-shore outsourcing are considered as high risk (Lowe et al, 2009). There are many causes for the high risks, which are usually summarised as the "4Cs" - capability, compatibility, commitment and control. Capability risk is a main cause for delays of end product and service delivery due to the inability of suppliers to produce on time and to the required quality (Canbolat et al, 2007). Compatibility risks arise in working together and often do not emerge until the implementation phase. Such risks can arise as a result of differences in culture, management style, personality, and administrative and accounting procedures (Rudberg and West, 2008). Many alliances fail through a lack of staying power because partners are not willing to continue the commitment in resources and effort. Control risk is normally high for weaker partner(s) in a joint venture or strategic alliance. When one partner is dominant, then the weaker partner(s) may risk having its (or their) core competencies reduced or eliminated (Nagurney and Matsypura, 2005).

In today's highly competitive, fast paced global business environment, there is no room for error in making global co-ordination decisions. Companies' success (or survival) depends on the manufacturing managers' capability in making consistent, rational, optimal decisions. In order to succeed in such an unforgiving environment, manufacturing managers need efficient and effective support that can provide an appropriate level of decision analysis and assessment through using a wide range of models, along with data and information sources available to them.

This paper is concerned with integrated decision support for global manufacturing coordination across multiple functions and multiple (international) locations. A Global Context Modeller is defined to address the dynamics, complexity, uncertainty and risks of the business environment. Global manufacturing performance measurements are captured through a Multi-Criteria Scoring Modeller. The purpose is to integrate the Global Context Modeller and the Multi-Criteria Scoring Modeller within an integrated decision support system, which has the ability to align the manufacturing management decisions with the firm's global business environment and its performance objectives. A case study has been undertaken to evaluate the decision system in the automotive industry. The main 
contribution of this paper (to the body-of-knowledge in general and to global manufacturing co-ordination systems specifically) is that it advances the state-of-the-art in model-driven decision support systems, by addressing the most commonly stated shortcomings of the traditional methodologies including lack of model integration, and lack of model usability/accessibility.

The paper is organised as follows: Section 2 reviews work in relation to decision making and support in global manufacturing. Then an integrated decision support system is proposed to support the decision making in Section 3. Section 4 discusses the issues related to integration and the system implementation. The evaluation of the decision support system is discussed in Section 5 before conclusions are drawn in Section 6.

\section{Literature review}

Decisions in global manufacturing can be classified into two types of structures: centralised and decentralised (Canbolat et al, 2007). Within a decentralised decision structure, local decision makers can make decisions based on their own goals and preferences, without constraints from their suppliers, consumers or partners. In fact, in this case the coordination effect along the manufacturing network at global level is minimal. One severe consequence of decentralised decision making is that it can lead to a loss of control for the upper-level managers in the OEMs, Systems Integrators and Global Standardisers. As a result, the OEMs will not be able to deliver the products and services to customers to meet the specified performance criteria. Therefore, many argue that co-ordination decisions need to be centralised so that decisions across different functions and locations in the whole manufacturing network are well co-ordinated (Acar et al, 2010). Research has shown that centrally co-ordinated decisions are more advantageous. Within the centralised decision structure, decision makers at different organisational levels aim to resolve conflicting interests and work towards one common goal, i.e. to meet the global manufacturing network overall performance objective. Upper-level managers at OEMs, Systems Integrators and Global Standardisers can interfere with lower level decisions when needed (usually only in "exceptional" circumstances) (Kouvelis and Gutierrez, 1997). There are, however, implementing and control difficulties associated with central co-ordination which needs more investigation. For example, the decision dependencies within the whole decision network can become really complex. Therefore, decision management such as decision propagation path and decision change has to be well addressed. This paper attempts to address the issues concerning the centralised decision structure, and explores how this type of decision can be supported through advanced ICT technologies and systems.

Decision support system (DSS) is a well-established research and development area, originating from Computer Science and Organisation Management represented by the work undertaken by Simon et al at the Carnegie Institute of Technology and by Gerrity et al at MIT, during late 1950s and early 1960s (Keen and Morton, 1978). A DSS is defined as an interactive computer-based system that is designed to support solutions to decision problems (Bhatt and Zaveri, 2002; Shim et al, 2002). DSS research and its applications evolved significantly over time. DSS's power in handling large amount of information with speed and accuracy together with its capability of computing for complex analysis has made it an idea aid for decision makers. In global manufacturing, diverse DSS have been

\section{Deleted: the}

Deleted: in

Deleted: pronounced
Deleted: nce

Deleted: mutual 
developed to support various types of decisions, including systems that could support facility location (Canbolat et al, 2007), supply network planning and control (Leu et al, 2008; Dreyer et al, 2009), multi-site capacity planning and control, demand management, outsourcing decisions (Loebbecke and Huyskens, 2009), simulation and optimisation (Tyagi et al, 2004).

A closer look into the literature on DSS for global manufacturing reveals that most DSS can be classified as data-based. Data-based DSS argue for the utilisation of ICT as enablers for immediate access to information/ knowledge and thus reduce response time and increase flexibility (Guerra-Zubiaga and Young, 2006; Young et al, 2007; Dreyer et al, 2009). For example, a DSS utilising distributed artificial intelligence techniques (mobile agents in particular) is developed for the transfer of product design and manufacturing information throughout the global manufacturing network (Nassehi et al, 2006; Newman et al, 2008). With the support from the intelligent DSS, distributed decision makers can make the right decisions on the manufacturing resources and process plans to achieve interoperability between disparate manufacturing venues.

Provision of the right information and knowledge is important to decision makers. However, model-based DSS has gone one step further in supporting decision making. Along with the access to data and information resources at various internal and external repositories, model-based DSS can also provide the capability of decision analysis and evaluation based on a wide range of qualitative and quantitative models (Narasihan and Mahapatra, 2004; Phillips-Wren et al, 2009). Therefore, model-based DSS are advantageous over data-based DSS in terms of informing decision makers about the consequences of each decision alternative. There have been vast amount of interests and development recently in modelbased DSS for global manufacturing. Leu et al (2008) presented a DSS for global supply network configuration based on Linear Programming optimisation models. In (Canbolat et al, 2007), an integrated modelling approach brought together a decision tree and multi attribute utility theory for global manufacturing facility location decisions. A DSS using mathematical programming models for global network optimisation is discussed by Tyagi et al (2004).

Despite its wide application, existing model-based DSS have been heavily criticised. Some most commonly pronounced shortcomings include lack of model reusability (for single | purpose, throwaway efforts), lack of integration of models to the real world (isolation from the environment that they represent), and lack of model utility/accessibility (not available to non-modelling specialists and therefore with limited usage and value) (Delen and Pratt, 2006). To address the issues related to model integration and model utility/accessibility, first, this paper has developed the concepts of a Global Context Modeller and a MultiCriteria Scoring Modeller to adequately reflect the complexity, uncertainty and risks of $\underline{a}$ real-world global manufacturing environment. Second, the paper implements the models within an Integrated DSS (IDSS) based on a standard integration platform, where nonmodelling specialists can conveniently access the models through the platform's professional, user-friendly interface. The IDSS is designed and developed to support the decision making in global manufacturing co-ordination (i.e. management of the dependencies) across multiple business functions (manufacturing, transportation and 
distribution) and multiple geographical locations (different countries, continents and free trade zones).

\section{Key components of the IDSS}

Figure 2 shows the architecture of the integrated decision support system (IDSS). The architecture comprises three basic components inherited from traditional DSS and four new key components defined in this paper especially for global manufacturing co-ordination. DBMS (database management subsystem), MBMS (model base management subsystem) and UI (user interaction management subsystem) are considered as the three basic components for a traditional DSS (Hopple, 1988). The IDSS takes the concept of these three components and instantiates them in the scenario of global manufacturing. The main functions of the three basic components remain the same as in traditional DSS, i.e. to manage data, models and interaction with users, which have been well discussed in the literature (Carlsson and Turban, 2002). This section focuses on the four key components (proposed in this paper), i.e. a Global Context Modeller (GCM), a Multi-Criteria Scoring Modeller, a Configurator, and a Co-ordinator.

\subsection{Global Context Modeller (GCM)}

The purpose of defining the Global Context Modeller (GCM) is to provide the decision makers with an appreciation for the complexity, uncertainty and risks of the global business environment at which co-ordination decisions are situated. The global manufacturing context can be identified from different perspectives, for example, from strategic, organisational and environmental perspectives. To manage the characteristics of a global manufacturing context, the GCM captures the information of the identified factors, and classifies them in three main categories. Figure 3 is a class diagram of the global manufacturing context represented with SysML (Weilkiens, 2008). For the Environmental Context class, five sub-classes have been further defined: Economy, Social and Cultural Differences, Technology, State and Politics, and Labour Market. For the Organisational Context, four sub-classes are defined: Structure, Ownership, Size and Goals. Two sub-classes for the Strategic Context are Management and Leadership Style, and Business ethics. Attributes have been specified for all classes to capture further details of the factors. For example, important attributes of the State and Politics class include: membership of a free trade agreement (such as NATO, EU, NAFTA), investment incentives (regarding taxes, energy etc.), demand (sales market), and infrastructure. The stability of the State and Politics can be considered as either stable, disturbance likely (e.g. occasional violence) or not stable (e.g. regular war zone). The whole point of capturing global manufacturing context information through the classes and attributes is to allow the decision makers to use the right information to gauge the likely level of uncertainty and risks of the business, to appreciate the complexity and dynamics of environment, and make informed decisions.

To assess specific characteristics of global manufacturing, managers need to find all necessary information by searching through a series of classes modelled in the GCM. Table 1 gives examples of information captured in relevant classes and attributes that can be used to assess the characteristics of uncertainty and risk (the definitions of the characteristics have been discussed in Section 1). As Table 1 shows, to assess uncertainty, information from

\begin{tabular}{l} 
Deleted: to \\
Deleted: $\mathrm{e}$ \\
\hline Deleted: G \\
\hline
\end{tabular}

Deleted: include

Deleted: organise

Deleted: the

Deleted: together from

Deleted: the 
the following classes can be used: State and Politics (Stability and Infrastructure attributes), Economy (Exchange rate attribute), Supply Networks (both Supply Side and Demand Side), and Technology (affecting lead-time). To estimate different aspects of the risks, information from the following classes and attributes can be used. For capability assessment, users can use Technology, Size, Infrastructure and Labour Market. Similarly, for compatibility assessment, classes of Technology, Social and Cultural Differences, Management and Leadership Style, and Business Ethics, can be used. Ownership can be used to assess control factor, and Goals class can help assess commitment aspect. The impact of uncertainty to decision making is that decisions will be made on inaccurate information if uncertainty is not anticipated, for example if the fluctuation of demand is not considered, then manufacturers may either have insufficient capacity to deal with extra demand, or have excess capacity and waste resources when the demand is actually lower. Lack of information about risks in the "4Cs" (not able to fulfil the Capability, Compatability, Commitment and Control as defined in Section 1), decision makers could make wrong decisions. For example, when decision makers are not informed of manufacturing networked resources and their capabilities, it is impossible for them to formulate potential alternatives and make rational choices.

Based on the information captured and organised in the global manufacturing context, GCM can then provide a qualitative assessment of the factors for each facility involved in the global manufacturing network, quantifiy the attributes through weighting according to the manufacturing manager's domain knowledge and the decision maker's preferences, calculate the aggregated value of the factors, and estimate the potential uncertainty and risk level for the partnerships.

\subsection{Multi-Criteria Scoring Modeller (MCSM)}

Decision criteria for global manufacturing depend on the metrics adopted for the measurement of manufacturing network performance. The definition of manufacturing network performance has been broad because a company's mission, strategy and objectives can vary considerably based on the value of the products offered to the customers (Meixell and Gargeya, 2005). Although real world manufacturing networks emphasise a variety of performance measures in practice, many argue that commonality does exist and fundamental measures can be identified. For example, the five performance objectives proposed in (Slack et al, 2010) are widely accepted. They are cost, quality, speed, dependability and flexibility. Earlier, the Supply Chain Council (2003) identified five performance metrics as cost, assets, reliability, flexibility and responsiveness. Under globalisation, some researchers also recognise access to new technologies and broadened supply base as benefits (Needle, 2005). The sharp economic downturn in recent years has led to an increased emphasis on cost reduction. This paper takes the view that no single performance metric can sufficiently represent the complexity of global manufacturing, and therefore treats the global manufacturing co-ordination as a multi-criteria decision problem. Subsequently a Multi-Criteria Scoring Modeller (MCSM) is proposed to address the decision problem.

For decision makers, a multi-criteria decision problem that requires a trade-off among the several criteria is difficult to solve (Nagurney and Matsypura, 2005). In this section, an MCSM is defined to assist in analysing the global manufacturing co-ordination problem and help identify the preferred decision alternative. The MCSM has the following five functions: 
Function 1. Develop a list of the criteria to be considered. For the global manufacturing coordination decision problem, five criteria have been considered based on the recommendations from (Slack et al, 2010) and the Supply Chain Council (2003): cost, quality, reliability, flexibility and responsiveness (speed).

Function 2. Assign a weight to each criterion that describes the criterion's relative importance. In the IDSS, $\mathrm{w}_{\mathrm{i}}$ represents the weight for criterion $\mathrm{i}$.

Function 3. Assign a rating for each criterion that shows how well each decision alternative satisfies the criterion. In the IDSS, $r_{i j}$ is used to represent the rating for criterion $i$ and decision alternative $\mathrm{j}$.

Function 4. Calculate the score for each decision alternative. In the IDSS, $S_{j}$ represents the score for alternative $\mathrm{j}$. The equation used to compute $\mathrm{S}_{\mathrm{j}}$ for each alternative is

$$
S_{j}=w_{1} r_{1 j}+w_{2} r_{2 j}+w_{3} r_{3 j}+w_{4} r_{4 j}+w_{5} r_{5 j}
$$

Function 5. Order the decision alternatives from the highest score to the lowest score to provide the MCSM's ranking of the decision alternatives.

To realise Function 2, i.e. assign a weight to each criterion to indicate the criterion's relative importance perceived by decision makers in a specific decision making process, a five-point scale is specified in which a five means very important and 1 unimportant. By repeating this question for each of the five criteria, the MCSM can capture the weightings assigned by decision makers and record them in the database for later calculation of $\mathrm{W}_{\mathrm{i}}$.

To realise Function 3, i.e. rate each decision alternative in terms of how well it satisfies each criterion, a nine-point scale system specified by Saaty (2005) is employed.

The scoring process must be completed for each combination of decision alternatives and decision criterion. Assuming the number of decision alternatives is $\mathrm{N}$, and because five decision criteria must be considered, then a total of $5 \times \mathrm{N}$ ratings must be provided and captured in the MCSM. When $\mathrm{N}$ is big such as over a hundred, without support from computer systems it is impossible for human decision makers to comprehend the appropriateness of all the decision alternatives against decision criteria, in which case the benefit of having the MCSM is considerable. The results of Function 2 (weighting the decision criteria) and 3 (rating decision alternative against each decision criterion) will enable Function 4 to calculate the overall satisfaction of decision alternatives based on the aggregated weight of all decision criteria.

It should be noted that quantitative measures have been used for the cost criterion, in which aggregated cost has been considered (Newnes et al, 2008). The mathematical model for the aggregated cost calculation (so far information about four types of cost elements is collected and captured in the IDSS) is formulated as:

Aggregated cost $=\sum C_{p}+\sum C_{i}+\sum C_{e}+\sum C_{t}$

Where $C_{p}$ : production cost incurred for a particular component;

$\mathrm{C}_{\mathrm{i}}$ : inventory cost incurred for a particular storage location or warehouse;

$\mathrm{C}_{\mathrm{e}}$ currency exchange cost incurred for a particular transaction;

$\mathrm{C}_{\mathrm{t}}$ : transportation cost incurred for a particular movement of products.

To sum up, the MCSM utilises a combination of quantitative (for cost criterion) and qualitative (for other criteria) assessment to provide analysis of the decision alternatives.

Deleted: $\Sigma($
Deleted: )

Deleted: the

Deleted: Table 2 shows, relative to other criteria that are considered, how important Cost is.

Deleted: the
Deleted: is
Deleted: Table 3 shows, to what
extent, alternative j satisfies criterion i.

Deleted: the

\section{Deleted: the}

Deleted: s

Deleted: the

Deleted: s

\begin{tabular}{|l|}
\hline Deleted: to \\
\hline Deleted: to \\
\hline Deleted: to \\
\hline Deleted: to
\end{tabular}




\subsection{Configurator}

The Configurator provides the IDSS with the capability of organising the facilities into a manufacturing network. The key for the Configurator to generate a manufacturing network is to understand the organisational structures such as the flat structure shown in the Figure 1. Each facility's function and characterisation (as OEM, System Integrator, Global Standadiser, System Manufacturer, Component Specialist, or Raw Material Supplier) should be identified and the information needs to be stored in the system database in advance, and ready for the Configurator to query.

\subsection{Co-ordinator}

The Co-ordinator is designed to manage decision hierarchies and dependencies among the OEM, Systems Integrators, Global Standardisers, Systems Manufacturers, Component Specialists and Raw Material Suppliers in a manufacturing network if a flat structure is configured by the Configurator. Alternatives of co-ordination strategy and mechanism are also provided.

\section{Integration and system implementation}

\subsection{Relationships between the four key components}

While the four components have their distinguishing roles and functions, the specification of the relationships between the components holds the key for integration. Integration was and remains to be one of the most often used words, yet poorly defined notions (Ding et al, 2009; Liu et al, 2010). However, it is widely accepted that integration is a property of component (in the form of models, services, tools, methods, systems, or subsystems) interrelations. Therefore, it is believed that the key notion is the relationships and the nature of these relationships. In the context of IDSS, integration means sharing of consistent and current information, sharing of model analysis functions (through remote service calls), and sharing a common decision making process through co-ordinated activities (triggered at the right time for the right decision makers in the right order).

This section discusses the modelling of the relationships with SysML (Systems Modelling Language). SysML is a visual modelling language and an evolution of UML (Unified Modelling Language). SysML aims to support the audience in Systems Engineering, particularly to allow them to address the integration of systems (Neaga and Harding, 2005; Weilkiens, 2008). The main reasons to choose SysML for modelling IDSS is that, with SySML, the complex relationships between the four key components, i.e. the GCM, the MCSM, the Configurator and the Co-ordinator can be better represented, communicated and understood. Furthermore, SysML tools provide the mechanism for the models to be transformed into programming languages such as Java, which could save the system developers considerable time and effort in code generation.

Key relationships between the four key components in the IDSS have been defined and represented using SysML component models, as shown in Figure 4. In SysML, component diagrams define how components/ subsystems are collected into a high level system, and interfaces (through ports) and connections between them. As shown in Figure 4, between the four key components, communication of the messages are directed through twelve

Deleted: ed

Deleted: the

Deleted: M

Deleted: because

Deleted: codes 
dedicated pairs of ports. The nature of the relationships is attached as labels on each connection. For example, the key information provided to other modules by the Global Context Modeller is global manufacturing context (discussed in Section 3.1). Information provided by the Configurator includes all configuration types for the manufacturing network. The Multi-Criteria Scoring Modeller provides decision evaluation results against decision performance metrics. Finally, the Co-ordinator provides the information about decision dependency and propagation path. The ports will be mapped to the computer network within the IDSS. By understanding the relationships between the four key components and how the information and functions can be efficiently and effectively communicated through dedicated interacting points (i.e. the port-pairs), it ensures that the right information and functions are available at the right time in the right place for the right decision makers.

\subsection{The Integration platform}

The IDSS is implemented by adopting a professional integration platform, namely the SAP ERP NetWeaver, which is provided by SAP (one of the world's leading companies in professional software). SAP ERP NetWeaver supports enterprise management using Web Services Technology. Since the 1970s there have been major technology waves in software solutions: from the mainframe computing to client and server architecture, and now to service-oriented networks ( $\mathrm{Ng}$ and $\mathrm{Ip}, 2000$ ). The services provided by the SAP ERP NetWeaver platform utilise the portal's capabilities, making use of the SAP Business Information Warehouse and the Strategic Enterprise Management functions such as balanced scorecard and management cockpit (Malik, 2005). SAP ERP Netweaver is an open platform. The four key components discussed in Section 3 are firstly developed as independent modules using Java programming (facilitated by an automatic code generation function provided by the SysML software Enterprise Architect $\left.{ }^{\circledR}\right)$. The individual modules then undergo Unit Test. When the functions of each module are texted to be valid, all four modules are then integrated using the SAP ERP Netweaver adaptors, which allows users' own modules and tools to be plugged-in and play. Altogether, the newly developed modules and the ERP Netweaver platform form the IDSS. Technical details of the system implementation based on SysML modelling, Java programming and integration platform have been discussed in authors' previous publication (Liu et al, 2009). Equipped with the IDSS, decision makers can use the various functions from the four key components to produce multiple dimensional analysis. Decision makers can also use the functions embedded within the Netweaver, such as the visualised decision dashboards (a screenshot is shown in Figure 5), to inform their decision making process. The evaluation of the IDSS with a case study in the automotive sector is discussed in the next section.

\section{Evaluation of the IDSS through a decision case}

| This case study is based on the information collected from Aeolus Automotive Corporation (AAC), currently ranked the second largest in the automotive industry in China. Its main foreign joint investors include French Citroen, Japanese Honda and Korean Kia. Back in 1999, AAC was able to produce a total number of 257,000 vehicles, with production mainly focusing on heavy-duty, medium-sized, and light-duty trucks. The joint investment with Citroen enabled them to produce Fukang sedans. As a penefit of the joint ventures from Japan and Korea, AAC now also produces Forte (Kia), Bluebird, Nissan GT-R and Honda

Deleted: which allows users' own modules and tools to be plugged-in and play

Deleted: from the SysML models

Deleted: are

Deleted: ne

Deleted: , and

Deleted: to

Deleted: will be

Deleted: The automotive sector still remains one of the fast moving industries even though Original

Equipment Manufacturers (OEMs) in the triad regions (Europe, Japan and US)

have been facing a mature market for the past two decades, with stagnant demand, product proliferation and stiff price competition (Wee and Wu, 2009). As a result, most OEMs have invested heavily outside their home base to better reach global markets and access to global resources, which resulted in the emergence and fast growth of numerous rising stars across Asia represented by China, India, North Korea and ASEAN (Association of SouthEast Asian Nations, including Indonesia, Malaysia, Plilippines and Thailand) (Veloso and Kumar; 2002).

Deleted: B

Deleted: ed from 
Teana sedans. Today, their products cover different ranges of final products, systems, subsystems, and components for trucks, cars and coaches, which have a substantial market share in China and Asia, and are accessing American and African markets. As of 2007, AAC produced an output of over 1.1 million vehicles. The whole manufacturing network of $A A C$ is complex and truly global.

The key co-ordination issues encountered by AAC/Honda Teana is the management of a mixture of two types of dependencies, i.e. type one dependency - between different activities (production, inventory and distribution), and type two dependency - between comparable activities in different geographical locations (across nations, regions, continents and free trade zones). The illustration of the application of the IDSS to the AAC case uses three key assumptions. The first assumption is: to take one product type, i.e. the Honda Teana sedan, out of all product ranges as an example. Assumption 2: the discussion limits the customers to Asian and American markets only. The third assumption is: three main functions along the manufacturing network are considered - production, inventory and transportation.

\subsection{Experimental design and data collection}

Based on the above three assumptions, a simplified mini manufacturing network for the Honda Teana - the CRV model - sedan (as shown in Figure 6) is formulated. The network includes: Two markets - Asian market (India, Pakistan and Tailand) and American market | (Brazil and Argentina); the Production network is represented by an OEM, one Systems Integrator, one Global Standardiser, two Systems Manufacturers, two Component Specialists, and one Raw Material Supplier. For most of them, there are choices of several potential suppliers. Specifically: The OEM - AAC HQ (China, Wuhan, short for CHN-WH); Systems Integrator - Chassis Integrator (CHN-WH or CHN-XF); Global Standadizer - Honda $\mathrm{HQ}$ (Japan-H); Systems Manufacturers - lighting system (CHN-GZ or Malaysia-L) and cooling system (CHN-XF or Singapore-L); Component Specialists - engines (Japan-H) and gear boxes (CHN-SY or CHN-XF or CHN-LZ); Raw Material Suppliers - steel (CHN-DB or CHN-HB or CHN$\mathrm{HN}$ ). Data collected from the company's manufacturing specialists include: product order history spanning twelve months in 2007 for the Honda CRV model sedan, production costs (of raw materials, components, systems, and assembly), transportation costs (domestic and international), inventory costs, and import tariffs for the countries involved. Context data of potential facilities, given by the manufacturing specialists in AAC on selected environmental and organisational factors, are summarised in Table 2. These data are captured in the GCM, populated and stored in the IDSS database in advance of the experiment.

\subsection{The decision procedure}

Figure 7 outlines the decision procedure for the decision case by linking the listed activities in the boxes. The Figure also illustrates the order in which the four key components participate in the decision procedure. The direction of arrows shows the information flow between the activities. The nature of the information flowing through the components is labelled on the arrows. As can be seen from the Figure, GCM retrieves the context information for facilities, quantifies the data, and generates an aggregated value for all the context factors. The outputs from the GCM should enable manufacturing managers to have an appreciation of the uncertainty and risks that might exist. The uncertainty and risks are 
calculated based on the value of the attributes of relevant classes. Based on the calculation, facilities with high uncertainty and risks will be distinguished from those with low uncertainty and risks. The ones with high uncertainty and risks will be eliminated and the ones with low uncertainty and risks will remain as potential candidates, which will be saved into the IDSS database and to be used at a later stage for network configuration. The MCSM then takes all the configuration alternatives formulated by the Configurator for multicriteria analysis. The configurations with the lowest overall performance assessed by MCSM will be eliminated at this stage. Configuration alternatives with higher overall performance assessed by the MCSM are kept as feasible configurations, and are saved into the database for later use by the Co-ordinator. The Co-ordinator then defines dependencies between the facilities in the configuration, quantifies the dependency complexity, and identifies coordination strategies and mechanisms. In the end, the IDSS produces the combined results of a holistic analysis, which takes into account all three dimensions: the global manufacturing context dimension supported by the $\mathrm{GCM}$, the multi-criteria dimension supported by the MCSM, and the co-ordination complexity dimension supported by the Coordinator. The outputs of the holistic analysis will be the optimal configuration and coordination choice.

\subsection{Experimental results}

Based on the context information shown in the Table $\underline{2}$, IDSS assesses the uncertainty and risks of each potential facility in the Honda CRV case. The following Figure 8 shows the analysed results of the global context of the facilities, in a bar chart format. The results from Figure 8 show that all facilities have a relatively high value of the aggregated context stability, which means that the uncertainty and risks can be considered as relatively low. Therefore, all the facilities can be entered into the Configurator as potential candidates for consideration in the next stage.

Deleted: 7
Deleted: the
Deleted: 7
Deleted: next stage

Using the known information from Section 5.1, the Configurator can quickly identify the roles for all candidate facilities as OEM, Systems Integrators, Global Standardisers, System Manufacturers, Component Specialists, or Raw Material Suppliers. The Configurator then searches the IDSS database for the product structure, in this case the BOM (Bill of Material) for the Honda CRV sedan, which has been stored in the system beforehand. Because product distribution will closely depend on where customers are located, it is essential that markets are included in the configuration. The outputs of the Configurator execution will be all configuration alternatives for the manufacturing network under consideration. In this case, there are 360 in total (calculated based on the combination of the numbers of potential candidate facilities, i.e. $3 \times 3 \times 4 \times 1 \times 2 \times 1 \times 5$ ). Ten out of the 360 configurations have been extracted and shown in Table 3 , just to illustrate what the mini manufacturing networks look like. The large number of configuration alternatives implies the complexity of the co-ordination. Obviously it is not practical for the company to explore all of the alternatives (otherwise, the resources will be stretched very far and wide). How can the manufacturing managers identify good configurations that can best achieve the performance objectives? The MCSM will be able to better support the decision.

Deleted: it is
Deleted: was designed and
Deleted: illustrative
Deleted: the
Deleted: optimal
Deleted: help with


The above configuration alternatives are then taken as inputs to the MCSM for multi-criteria decision analysis. Subsequently, the MCSM assigns a weighting and rating for each criterion and configuration alternative, and computes the aggregated value of each configuration's overall performance against the multiple criteria. Figure 9 shows the analysis results of the 10 configurations. Based on the analysis from the MCSM, those configurations with the overall lowest scores will be eliminated at this stage. For example, configurations 3 and 7 both have very low overall scores, and therefore will not be taken to the next stage for further consideration. The other eight with higher overall scores are considered as feasible configurations, and will enter to the next stage.

Next, the Co-ordinator defines the dependencies between the facilities for the remaining eight configuration alternatives, quantifies the dependencies, and identifies the appropriate co-ordination strategies and mechanisms for the configurations. Table 4 illustrates the dependency and co-ordination requirements for the eight configurations. The complexity and difficulty of co-ordination is quantified based on the two types of the dependencies shown in columns 2 and 3. A similar scoring system as used for MCSM is employed in the Co-ordinator. The aggregated results of the co-ordination complexity and difficulty for the eight remaining configurations are shown in the last column in the Table $\underline{4}$

Finally, the IDSS holistically examines the results of the eight remaining configurations with respect to all three key dimensions (i.e. the environmental context, the overall performance against the multi-criteria, and the co-ordination complexity), then makes final recommendations based on the combined results. This is done through data visualisation, by generating Bubble Charts and displaying them on the system user interface, so that decision makers can have a quick glance to get an overall picture of the configurations. In the Bubble Chart, as shown in Figure 10 , the context dimension is illustrated on the horizontal axis, which means that the configurations further away to the right have lower uncertainty and risks. The multi-criteria dimension is expressed on the vertical axis, which means the configurations further away on the top have higher overall performance. The coordination complexity is represented by the size of the bubbles, i.e. the configurations with smaller sizes need less co-ordination efforts and therefore should be preferred. Based on this final holistic assessment, it is clear that configuration 10 has high overall performance, with relatively low uncertainty and risk from the business environment, but with considerable complexity of the dependency. Comparatively, configuration 4 has similar context uncertainty and risks, and co-ordination complexity, but with lower overall performance; Configuration 5 has the same level of overall performance as alternative 10, but with much higher instability from the environment. Therefore, configuration 10 would be the favourable choice to decision makers. However, configuration 10 has quite a big bubble size which indicates that a high level of complexity exists between business activities and geographical locations along the manufacturing network, and therefore a tight coordination strategy will be needed to manage the dependencies.

\section{Conclusion and future work}

This paper proposed an IDSS for global manufacturing co-ordination. The Integrated Decision Support System (IDSS) integrates four key components to capture information and to provide decision analysis that are crucial to global manufacturing decision making. A

Deleted: in

Deleted: The following

Deleted: 8

Deleted: 6

Deleted: 6

Deleted: 9

Deleted: $s$ 
combination of qualitative and quantitative methods has been explored for the decision evaluation and analysis. Decision makers can use the evaluation and analysis results to improve their judgement on the decision problems, and reach more rational and consistent decisions.

One of the key contributions from this paper is the definition of a Global Context Modeller (GCM) and a Multi-Criteria Scoring Modeller (MCSM). The GCM helps manufacturing managers to better understand the key characteristics of global manufacturing. The context information captured in and provided by the GCM can help decision makers to assess the uncertainty and risks, in a global context. The MCSM addresses the multiple criteria typical for global manufacturing. The five criteria cost, quality, reliability, flexibility and responsiveness (speed) are concurrently considered in the MCSM. The integration approach demonstrated by the IDSS facilitates current and consistent information sharing, function sharing, and process synchronisation across activities and geographical areas throughout the global manufacturing network. The information and evaluation capability provided by the four key modules in the IDSS (i.e. the GCM, the Configurator, MCSM and the Coordinator), can support global manufacturing managers to make more rationalised and informed co-ordination decisions. The decisions are aligned with the firm's business environments (through appreciation of global context) and its business performance (through aggregation of multi-criteria).

The IDSS was evaluated with a case study from the automotive industry. Both GCM and MCSM are generic to global manufacturing context and multi-criteria decision making. The configuration rules specified within the Configurator and the dependencies specified within the Co-ordinator can be modified and re-populated for other applications where the manufacturing networks have similar organisational structure.

Further research has been identified as exploring the IDSS application to other industries, such as electronics. A focus for future work will be on the study of the flexibility of the four modules, i.e. how much changes (if any) to the modules are needed for a new application and how much effort will be required for the changes. Future work will also seek to consolidate the scoring system for uncertainty and risk in the GCM. Quantitative methods will be explored for other decision criteria apart from the cost criterion in the MCSM. It is also the authors' intention to explore the multi-criteria decision making module with more advanced Analytic Network Processes instead of the currently used Analytic Hierarchy Process, in order to accommodate the interdependencies between the decision factors.

\section{References}

Acar, Y., Kadipasaoglu, S. and Schipperijin, P., 2010. A decision framework for global supply chain management modelling: an assessment of the impact of demand, supply and lead-time uncertainties on performance. International Journal of Production Research 48(11): 3245-3268.

Bhatt, G.D. and Zaveri, J., 2002. The enabling role of decision support systems in organisational learning. Decision Support Systems, 32:297-309. 
Canbolat, Y.B., Chelst, K. and Garg, N., 2007. Combining decision tree and MAUT for selecting a country for a global manufacturing facility. OMEGA The International Journal of Management Science 35: 312-325.

Carlsson, C. and Turban, E., 2002. DSS: directions for the next decade. Decision Support Systems, 33:105-110.

Delen, D. and Pratt, D.B., 2006. An integrated and intelligent DSS for manufacturing systems. Expert Systems with Applications 30: 325-336.

Ding, L., Ball, A., Matthews, J., McMahon, C.A. and Patel, M., 2009. Annotation of Lightweight Formats for Long-term Product Representations. International Journal of Computer Integrated Manufacturing. 22 (11): 1037-1053.

Doran, D., Hill, A., Hwang, K.S. and Jacob, G., 2007. Supply chain modularisation: cases from the French automobile industry. International Journal of Production Economics, 106: 311.

Dreyer, H.C., Alfines, E., Strandhagen, J.O. and Thomassen, M.K., 2009. Global supply chain control - a conceptual framework for the global control centre. Production Planning and Control 20(2): 147-157.

EIMaraghy, H.A. and Mahmoudi, N., 2009. Current design of product modules structure and global supply chain configurations. International Journal of Computer Integrated Manufacturing, 22: 483-493.

Guerra-Zubiaga, D.A. and Young, R.I.M., 2006. A manufacturing model to enable knowledge maintenance in decision support systems. Journal of Manufacturing Systems, 25: 122136.

Hopple, G.W., 1988. The State of the art in decision support systems, QED Information Sciences Inc. ISBN 0-89435-247-4.

Kazmer, D. and Roser, C., 2008. Analysis of design for global manufacturing guidelines. DETC2007: Proceedings of the ASME International Design Engineering Technologies Conference and Computers and Information in Engineering Conference, pp. 901-911.

Kazaz, B., Dada, M. and Moskowitz, H., 2005. Global production planning under exchangerate uncertainty. Management Science, 51(7): 1101-1119.

Keen, P. and Scott Morton, M., 1978. Decision support systems: an organisational perspective. Addison-Wesley Publishing.

Kouvelis, P. and Gutierrez, G.J., 1997. The newsvendor problem in global market: optimal centralised and decentralised control policies for a two-market stochastic inventory system. Management Science 43(5): 571-585.Lee, C.K.M., Lau, H.C.W., Ho, G.T.S. and Ho, W., 2009. Design and development of agent based procurement system to enhance business intelligence. Expert Systems with Applications, 36: 877-884.

Leu, J.D., Huang, Y.T., Chen and C.H.V., 2008. Advantage analysis of the global supply network configuration using air-cargo logistics centre in the free trade zone. Proceedings of the $38^{\text {th }}$ International Conference on Computers and Industrial Engineering. Vols 1-3: 1289-1301.

Liu, S., Duffy, A.H.B., Whitfield, R.I., Boyle, I.M. and McKenna,I., 2009.Towards the realisation of an integrated decision support environment for organisational decision making. International Journal of Decision Support Systems Technology 1(4): 38-58.

Liu, S., Duffy, A.H.B., Whitfield, R.I. and Boyle, I.M., 2010. Integration of decision support systems to improve decision support performance. Knowledge and Information Systems - an International Journal, 22: 261-286. 
Liu, S. and Young, R.I.M., 2004. Utilizing information and knowledge models to support global manufacturing co-ordination decisions. International Journal of Computer Integrated Manufacturing, 17: 479-492.

Loebbecke, C. and Huyskens, C., 2009. Development of a model-based netsourcing decision support system using a five-stage methodology. European Journal of Operational Research, 195: 653-661.

Lowe, T.J., Wendell, R.E. and Hu, G., 2009. Screening location strategies to reduce exchange rate risk. European Journal of Operations Research, 136: 573-590.

Malik, S., 2005. Enterprise dashboards: design and best practices for IT. John Wiley and Sons Inc.

Meixell, M.J. and Gargeya, V.B., 2005. Global supply chain design: a literature review and critique. Transportation Research Part E, 41: 531-550.

Mondragon, A.E.C. and Lynos, A.C., 2008. Investigating the implications of extending synchronised sequencing in automotive supply chain: the case of suppliers in the European automotive. International Journal of Production Research, 46: 2867-2888.

Nagurney, A. and Matsypura, D., 2005. Global supply chain network dynamics with multicriteria decision making under risk and uncertainty. Transportation Research Part ELogistics and Transportation Review, 41: 585-612.

Narasihan, R. and Mahapatra, S., 2004. Decision models in global supply chain management. Journal of Industrial Marketing Management, 33: 21-27.

Nassehi, A., Allen, R.D. and Newman, S.T., 2006. Application of mobile agents in interoperable STEP-NC compliant manufacturing. International Journal of Production Research 44(18-19): 4159-4174.

Neaga, E. I. and Harding, J.A., 2005. An enterprise modelling and integration framework based on knowledge discovery and data mining. International Journal of Production Research, 436: 1089 - 1108.

Needle, D., 2005. Business in context: an introduction to business and its environment $\left(4^{\text {th }}\right.$ edition). Thomson.

Newman, S.T., Nassehi, A., Xu, X.W., et al, 2008. Strategic advantages of interoperability for global manufacturing using CNC technology. Robotics and Computer-Integrated Manufacturing, 24(6): 699-708.

Newnes, L.B., Mileham, A.R., Cheung, W.M., et al, 2008. Predicting the whole-life cost of a product at the conceptual design stage. Journal of Engineering Design, 19(2): 99-112.

Ng, J.K.C. and Ip, W.H., 2000. The strategic design and development of ERP and RTMS. International Journal of Computer Integrated Manufacturing, 13: 138-150.

Nunes, A., Ferreira, J.J.P. and Mendonca, J.M., 2005. Distributed business process coordination: a functionally oriented infrastructure. International Journal of Computer Integrated Manufacturing, 18: 418-426.

Phillips-Wren, G., Mora, M. and Forgionne, G.A. and Gupta, J.N.D., 2009. An integrative evaluation framework for intelligent decision support systems. European Journal of Operational Research, 195: 642-652.

Pontrandolfo, P. and Okogbaa, O.G., 1999. Global manufacturing : a review for planning in a global corporation. International Journal of Production Research 37: 1-7.

Rudberg, M. and West, M.B., 2008. Global operations strategy: co-ordinating manufacturing networks. Omega, 36: 91-106.

Saaty, T.L., 2005. Theory and Applications of the Analytic Network Process: Decision Making With Benefits, Opportunities, Costs, and Risks. 3 edition. Rowans Publications. 
Slack, N., Chambers, S. and Johnston, R., 2010. Operations management ( $6^{\text {th }}$ edition), FT Prentice Hall.

Shim, J.P., Warkentin, M., Courtney, J.F., Power, D.J., Sharda, R. and Carlsson, C., 2002. Past, present and future of decision support technology. Decision Support Systems, 33: 111126.

Trappey, C.V., Trapey, A.J.C., Lin, G.Y.P., Liu, C.S. and Lee, W.T., 2007. Business and logistics hub integration to facilitate global supply chain linkage. Proceedings of the Institute of mechanical Engineers Part B - Journal of Engineering Manufacture, 221: 1221-1233.

Tyagi, R., Kalish, P., Akbay, K. and Munshaw, G., 2004. GE plastics optimises the twoechelon global fulfilment network at its high performance polymers division. Interfaces 34(5): 359-366.

Veloso, F. and Kumar, R., 2002. The automotive supply chain: global rends and Asian perspectives. Asian Development Bank.

Verdouw, C.N., Beulens, A.J.M., Trienenkens, J.H. and Verwaart, T., 2010. Mastering demand and supply uncertainty with combined product and process configuration. International Journal of Computer Integrated Manufacturing 23(6): 515-528.

Weilkiens, T., 2008. Systems engineering with SysML/UML: modelling, analysis and design. The MK/OMG Press, 2008.

Weston, R.H. and Cui, Z., 2008. Next generation of manufacturing systems. In: X.T. Yan, Ion, W.I. and B. Eynard, eds. Global design to gain a competitive edge: an holistic and collaborative design approach based on computational tools. Springer-Verlag, London, 701-710.

Young, R.I.M., Gunendran, A.G. and Cutting-Decelle, A.F., 2007. Manufacturing knowledge sharing in PLM: a progression towards the use of heavy weight ontologies. International Journal of Production Research, 45: 1505-1519. 


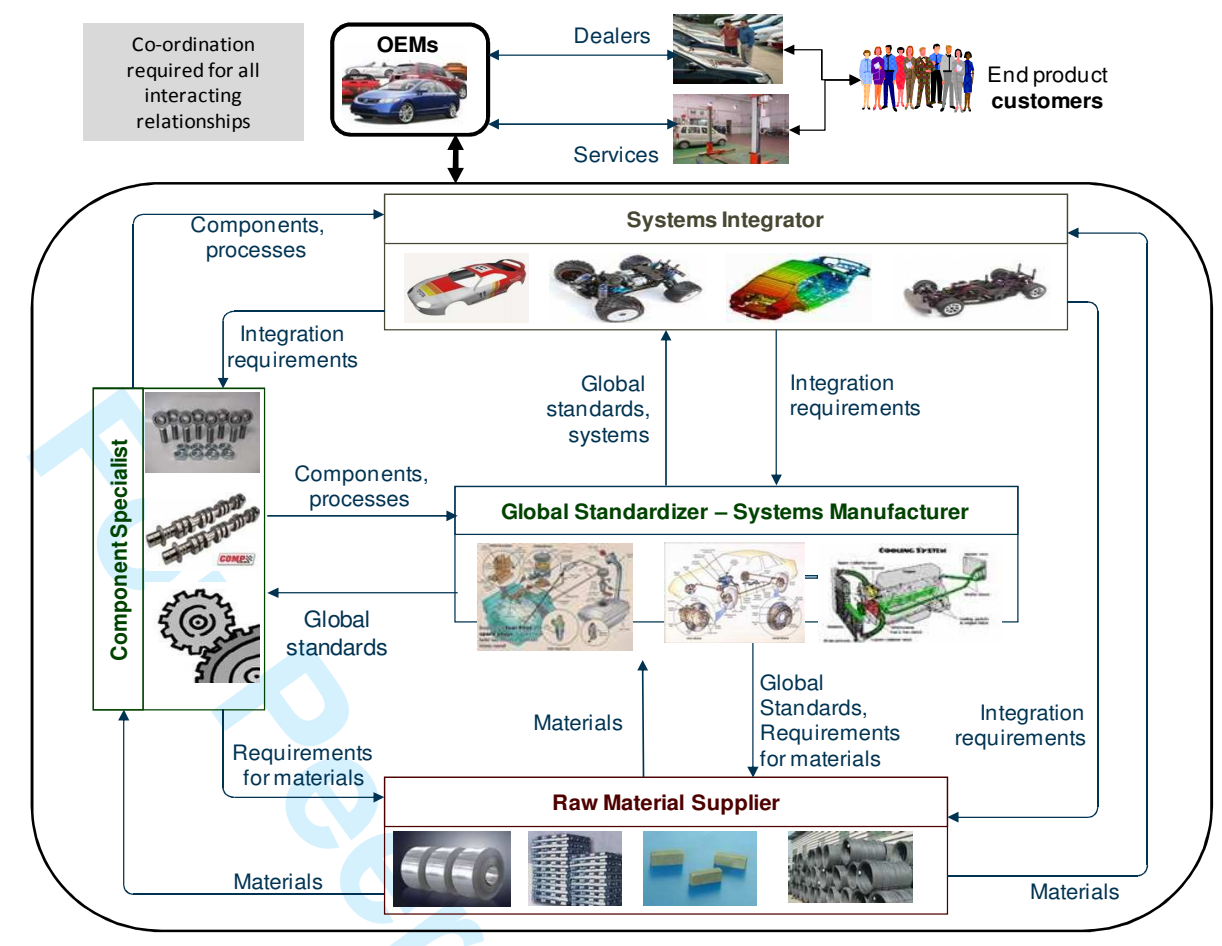

Figure 1 Interactions requiring co-ordination for the new flattened structure

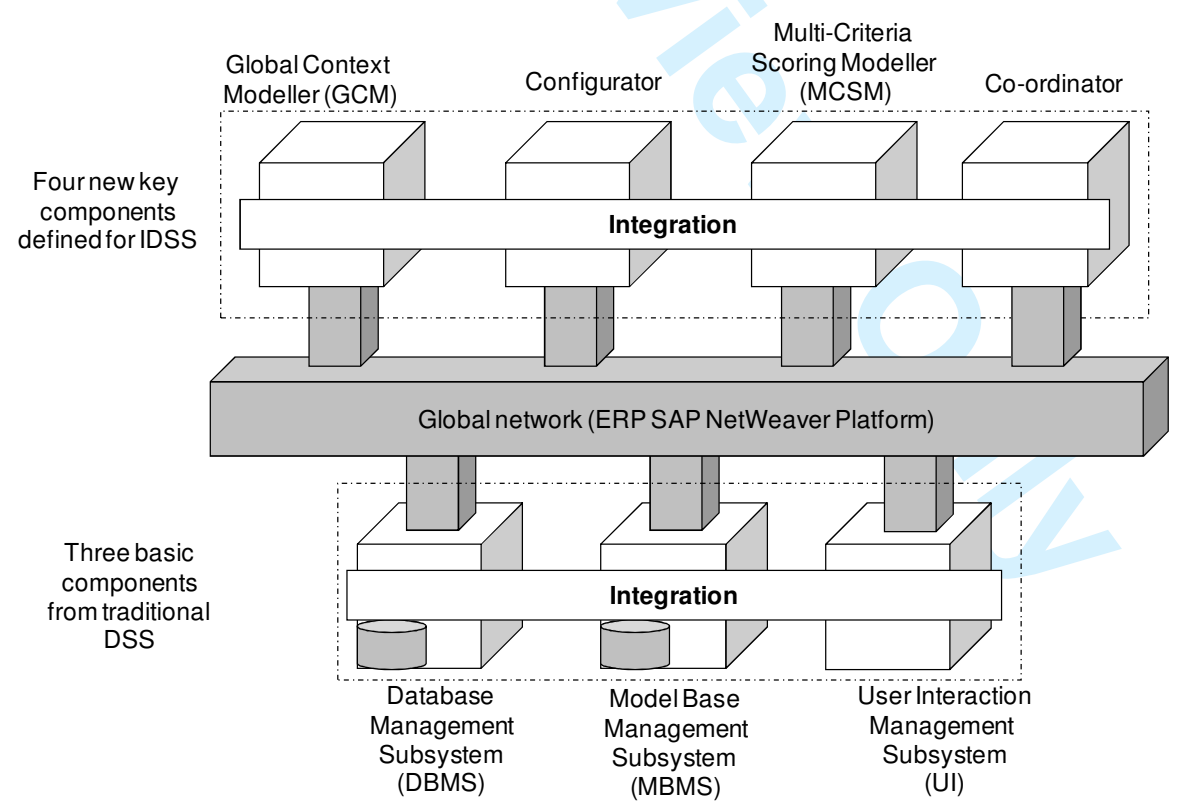

Figure 2 Architecture of the IDSS 


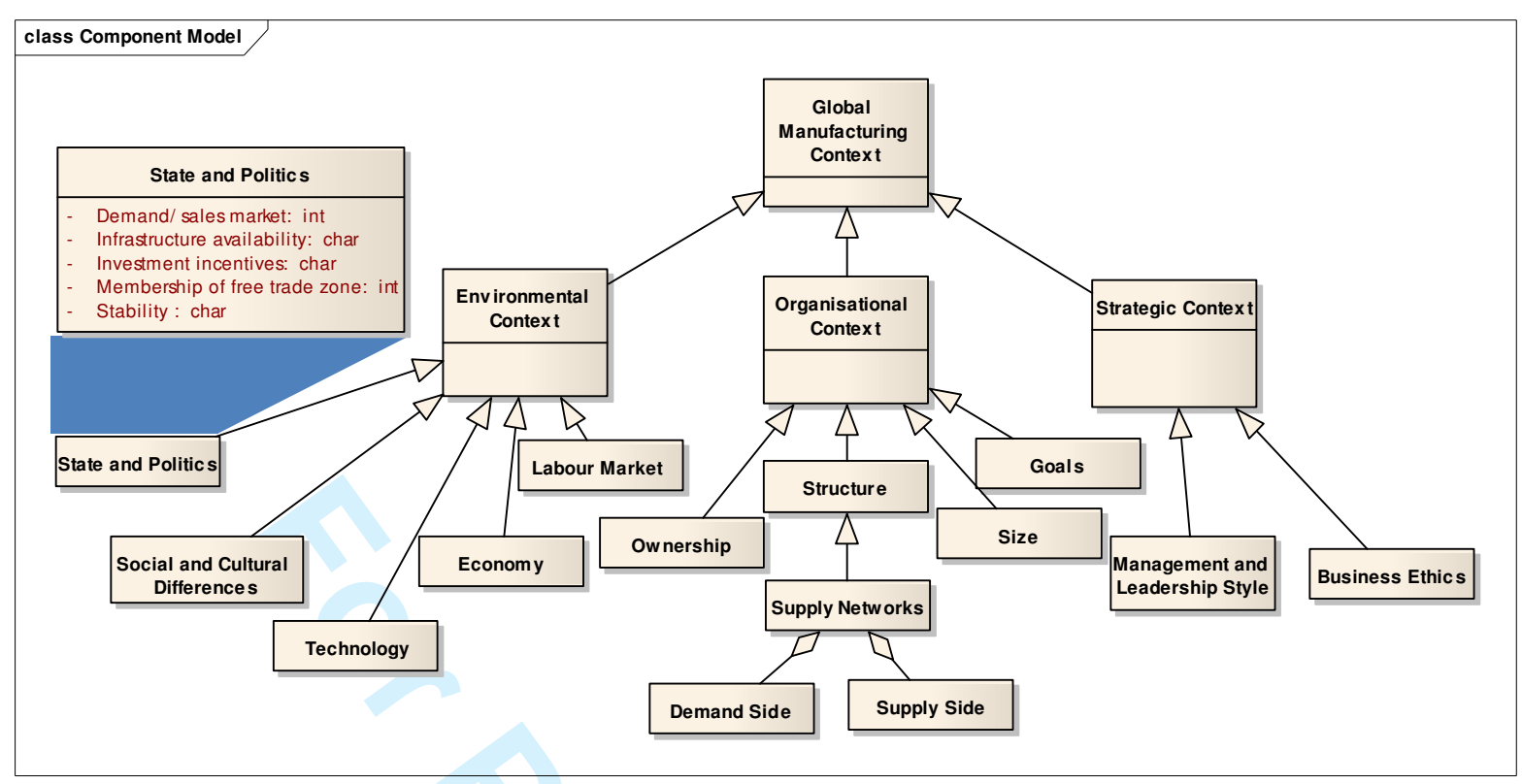

Figure 3 Class structure of the global manufacturing context

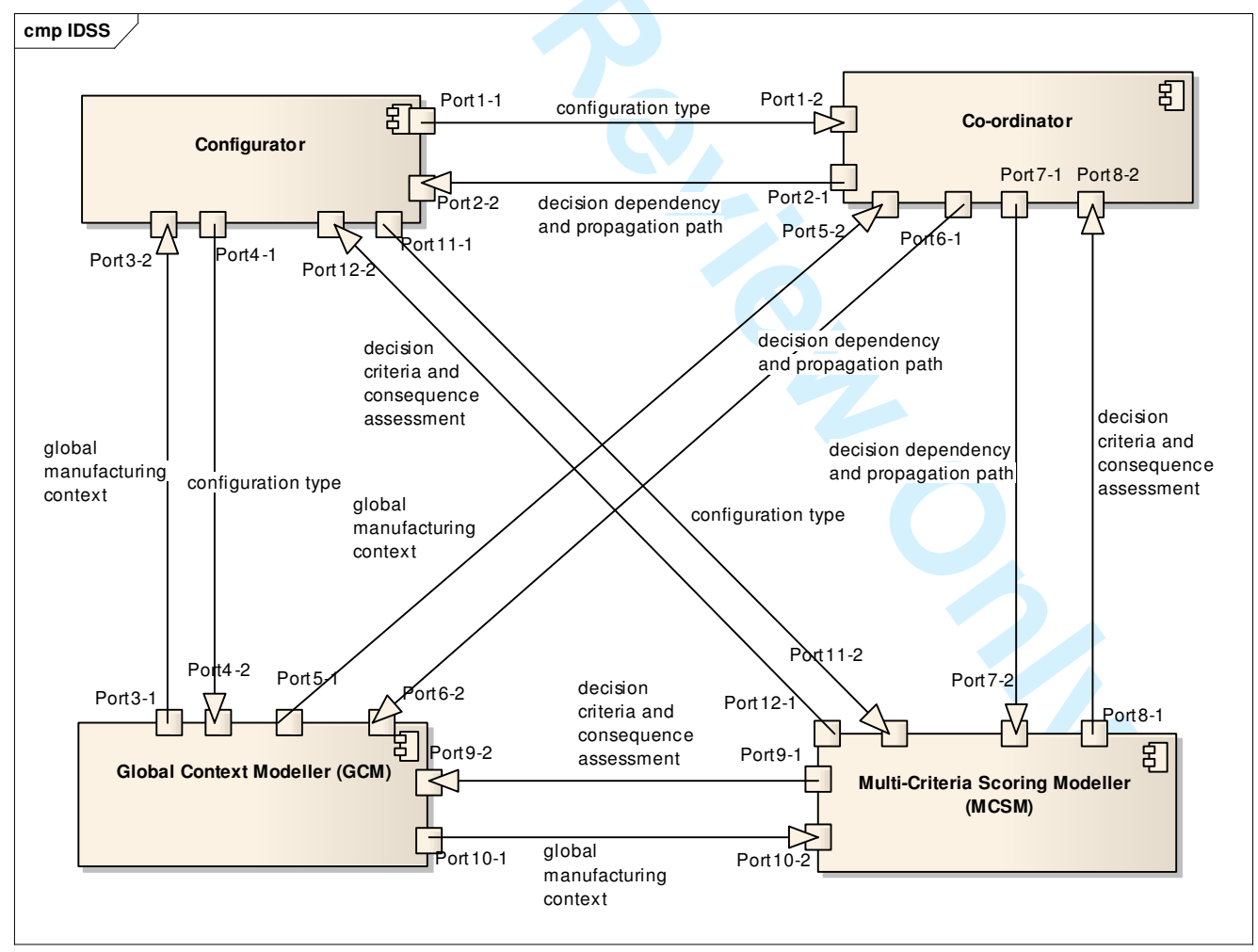

Figure 4 Relationships between the four key components in IDSS 


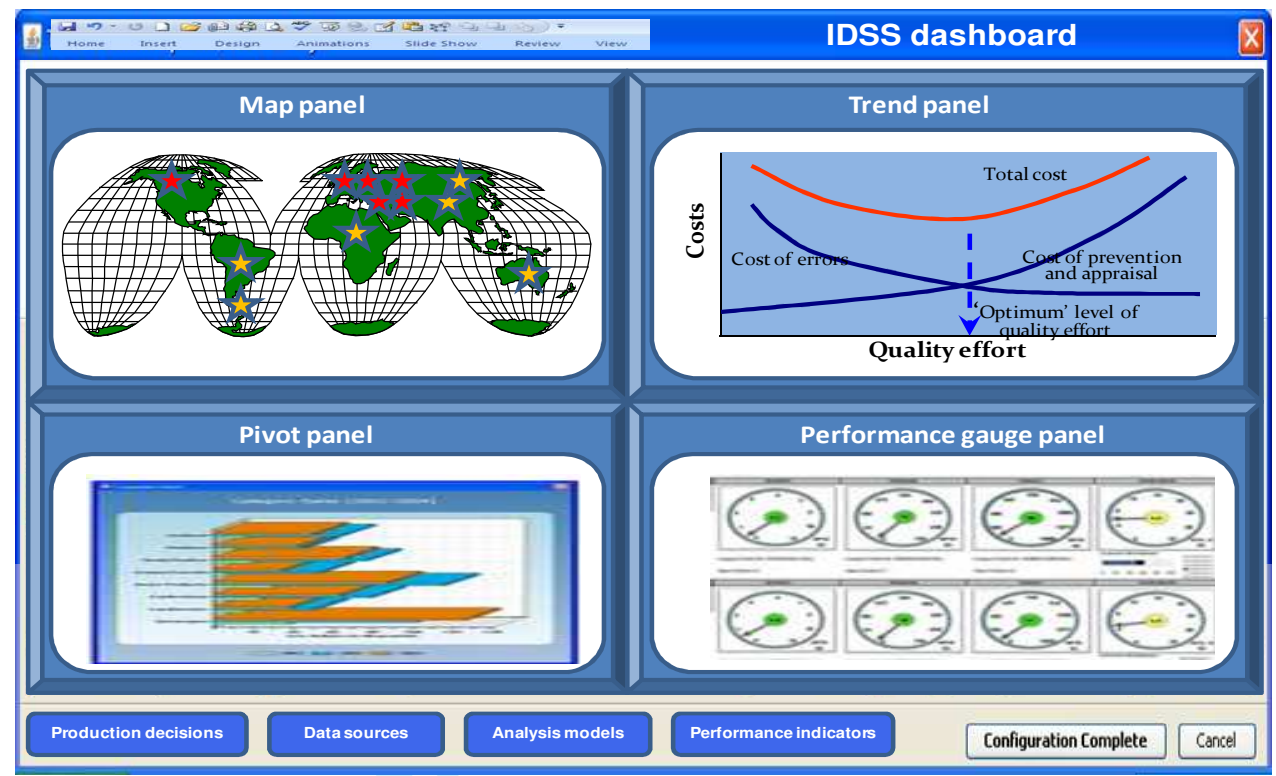

Figure 5 A screenshot of the decision dashboard

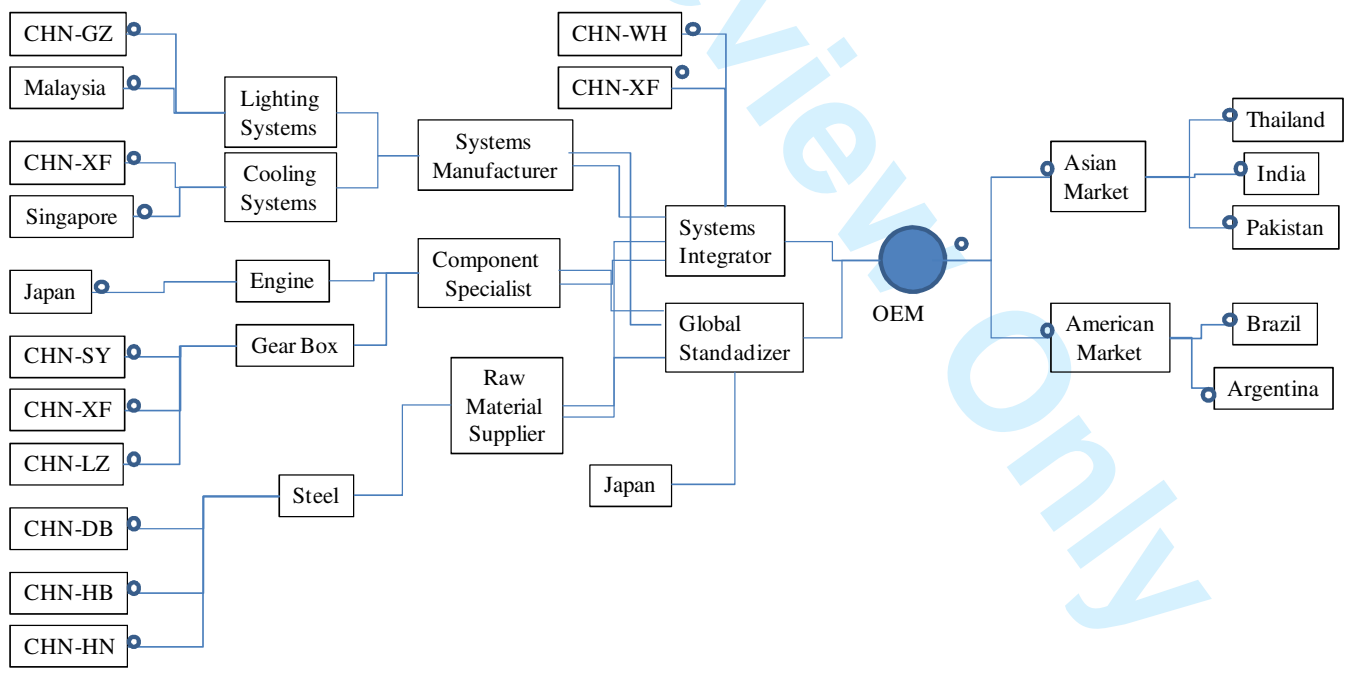

Figure 6 Simplified mini manufacturing network for the Honda CRV case 


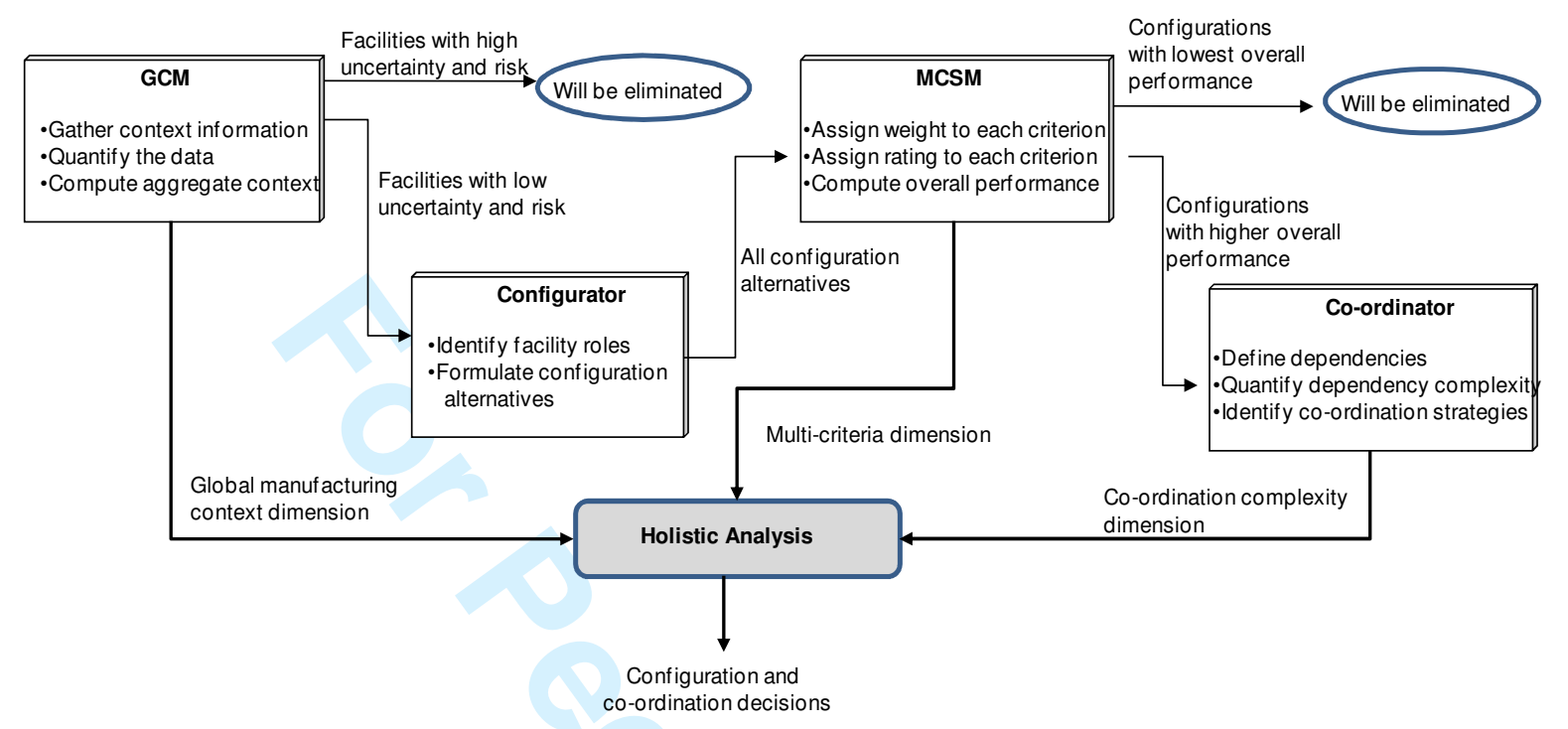

Figure 7 Activity and information flow within the decision case

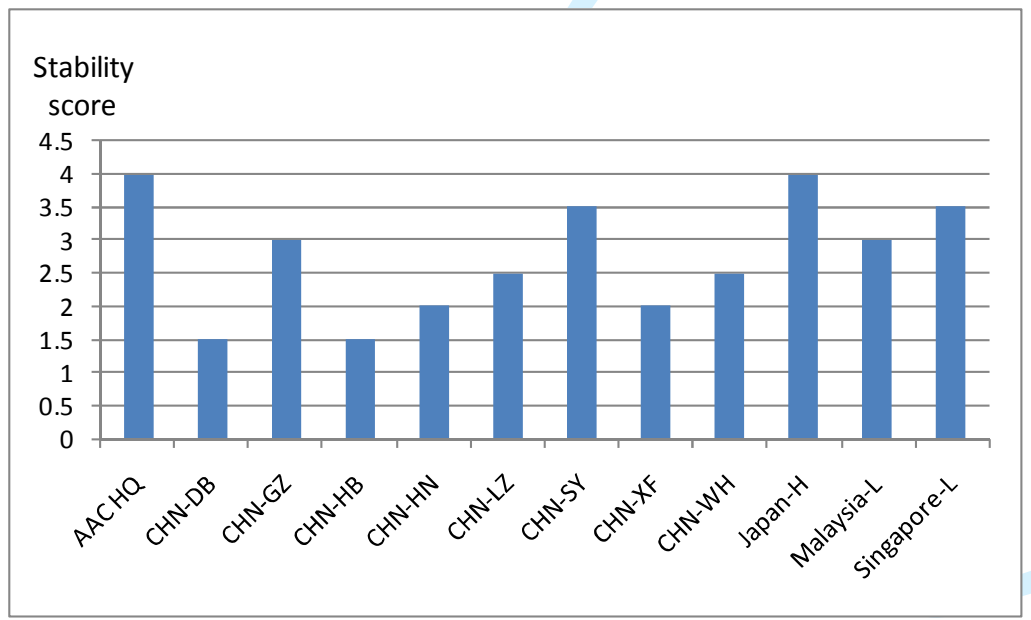

Figure 8 Analysis results of operations environment from GCM 


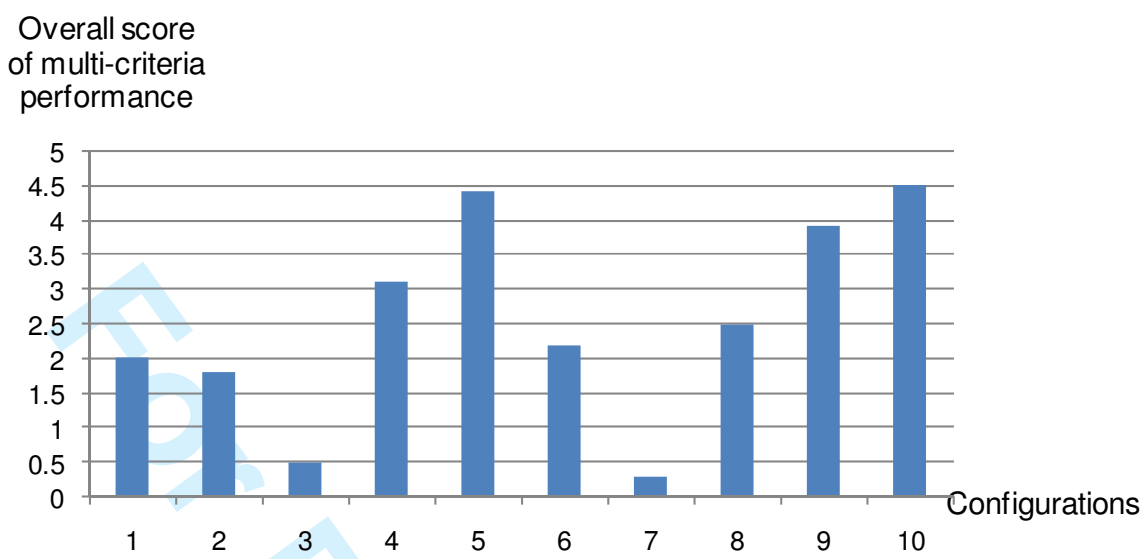

Figure 9 Analysis results of the overall performance for the ten configurations

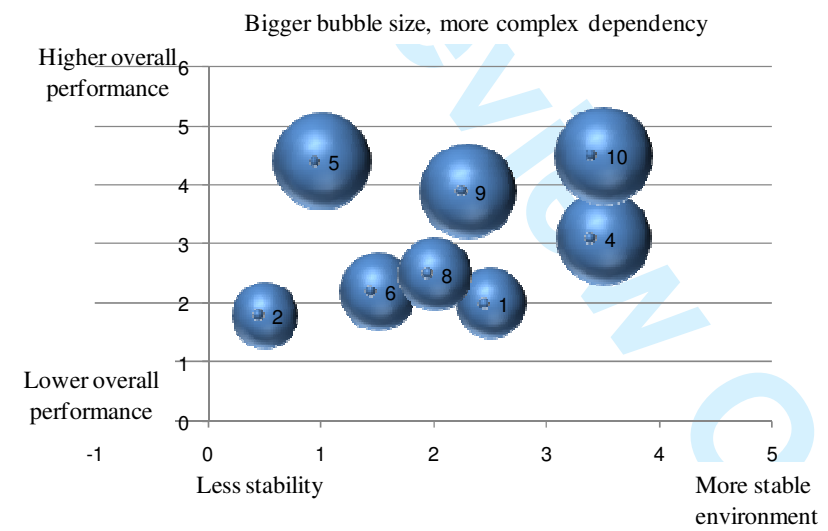

Figure 10 Combined value of the context, multi-criteria decision analysis and dependencies 
Table 1 Relevant information in GCM that can be used to assess uncertainty and risks

\begin{tabular}{|c|c|c|}
\hline \multirow{4}{*}{ Uncertainty } & $\begin{array}{c}\text { Representative indicators of the } \\
\text { characteristics }\end{array}$ & $\begin{array}{c}\text { Classes and attributes that captured relevant information in } \\
\text { GCM }\end{array}$ \\
\cline { 2 - 3 } & Lead time uncertainty & State and Politics, Technology, Infrastructure \\
\cline { 2 - 3 } & Supply uncertainty & Structure/ Supply Networks/ Supply Side \\
\cline { 2 - 3 } & Demand uncertainty & Structure/ Supply Networks/ Demand Side \\
\hline \multirow{3}{*}{ Risk } & Exchange rate uncertainty & Economy \\
\cline { 2 - 3 } & Mode of Entry & Structure/ Mode of Entry \\
\cline { 2 - 3 } & Capability & Social and Cultural Differences, Management and Leadership Style, \\
& Compatibility & Business Ethics, Technology \\
\cline { 2 - 3 } & Commitment & Goals \\
\cline { 2 - 3 } & Control & Ownership \\
\cline { 2 - 3 } & &
\end{tabular}

Table 2 Illustrative data collected and captured in GCM about global context of facilities

\begin{tabular}{|c|c|c|c|c|c|c|c|}
\hline & \multicolumn{5}{|c|}{ Environmental context } & \multicolumn{2}{|c|}{ Organisational context } \\
\hline $\begin{array}{l}\text { Facility } \\
\text { names }\end{array}$ & $\begin{array}{l}\text { Demand } \\
\text { fluctuation }\end{array}$ & $\begin{array}{l}\text { Supply } \\
\text { uncertainty }\end{array}$ & $\begin{array}{l}\text { Exchange } \\
\text { rate }\end{array}$ & $\begin{array}{l}\text { Technology } \\
\text { compatibility }\end{array}$ & $\begin{array}{l}\text { State/region } \\
\text { stability }\end{array}$ & Size & Ownership \\
\hline $\begin{array}{l}\text { OEM - } \\
\text { AAC HQ }\end{array}$ & Low & Low & $\begin{array}{l}\text { No } \\
\text { fluctuation }\end{array}$ & High & Stable & Middle & State owned \\
\hline $\begin{array}{l}\text { Japan- } \\
\text { Honda }\end{array}$ & Low & Middle & $\begin{array}{l}\text { Small } \\
\text { fluctuation }\end{array}$ & Middle & Stable & Large & $\begin{array}{l}\text { Limited } \\
\text { company }\end{array}$ \\
\hline $\mathrm{CHN}-\mathrm{XF}$ & Low & Low & $\begin{array}{l}\text { No } \\
\text { fluctuation }\end{array}$ & High & Stable & Large & State owned \\
\hline CHN-WH & Low & Low & $\begin{array}{l}\text { No } \\
\text { fluctuation }\end{array}$ & High & Stable & Large & $\begin{array}{l}\text { Limited } \\
\text { company }\end{array}$ \\
\hline CHN-GZ & Middle & Low & $\begin{array}{l}\text { No } \\
\text { fluctuation }\end{array}$ & High & Stable & Middle & $\begin{array}{l}\text { Private } \\
\text { company }\end{array}$ \\
\hline CHN-JX & Middle & Middle & $\begin{array}{l}\text { No } \\
\text { fluctuation }\end{array}$ & High & Disturbance & Small & State owned \\
\hline CHN-HB & Middle & Low & $\begin{array}{l}\text { No } \\
\text { fluctuation }\end{array}$ & Middle & Disturbance & Middle & $\begin{array}{l}\text { Private } \\
\text { company }\end{array}$ \\
\hline CHN-HN & Middle & Low & $\begin{array}{l}\text { No } \\
\text { fluctuation }\end{array}$ & Middle & Stable & Small & State owned \\
\hline CHN-DB & Middle & Middle & $\begin{array}{l}\text { No } \\
\text { fluctuation }\end{array}$ & Middle & Disturbance & Large & State owned \\
\hline Malaysia & High & High & $\begin{array}{l}\text { Small } \\
\text { fluctuation }\end{array}$ & Middle & Stable & Middle & Partnership \\
\hline Singapore & High & Middle & $\begin{array}{l}\text { Small } \\
\text { fluctuation }\end{array}$ & Middle & Stable & Small & Partnership \\
\hline
\end{tabular}

Table 3 Examples of the configuration alternatives for the Honda CRV mini manufacturing network

\begin{tabular}{|c|c|c|c|c|c|c|c|}
\hline & $\begin{array}{c}\text { Raw Material } \\
\text { Supplier } \\
(\mathbf{3}) \\
\end{array}$ & $\begin{array}{c}\text { Component } \\
\text { Specialist } \\
(1 \times 3) \\
\end{array}$ & $\begin{array}{c}\text { Systems } \\
\text { Manufacturer } \\
(2 \times 2) \\
\end{array}$ & $\begin{array}{c}\text { Global } \\
\text { Standardiser } \\
(1) \\
\end{array}$ & $\begin{array}{c}\text { Systems } \\
\text { Integrator } \\
(2) \\
\end{array}$ & $\begin{array}{c}\text { OEM } \\
\text { (1) }\end{array}$ & $\begin{array}{c}\text { Market } \\
\text { (5) }\end{array}$ \\
\hline 1 & CHN-DB & $\begin{array}{l}\text { Japan-H+CHN- } \\
\text { SY }\end{array}$ & $\mathrm{CHN}-\mathrm{GZ}+\mathrm{CHN}-\mathrm{XF}$ & Japan-H & CHN-WH & $\begin{array}{l}\text { AAC- } \\
\text { HQ }\end{array}$ & India \\
\hline 2 & CHN-HB & $\begin{array}{l}\text { Japan-H +CHN- } \\
\text { XF }\end{array}$ & Malaysia + CHN-XF & Japan-H & CHN-XF & $\begin{array}{l}\text { AAC- } \\
\text { HQ }\end{array}$ & Pakistan \\
\hline 3 & CHN-HN & $\begin{array}{l}\text { Japan-H + CHN- } \\
\text { LZ }\end{array}$ & CHN-GZ + Singapore & Japan-H & CHN-WH & $\begin{array}{l}\text { AAC- } \\
\text { HQ }\end{array}$ & Thailand \\
\hline 4 & CHN-DB & $\begin{array}{l}\text { Japan-H+CHN- } \\
\text { SY }\end{array}$ & Malaysia +Singapore & Japan-H & CHN-XF & $\begin{array}{l}\text { AAC- } \\
\text { HQ }\end{array}$ & Brazil \\
\hline 5 & CHN-HB & $\begin{array}{l}\text { Japan-H +CHN- } \\
\text { XF }\end{array}$ & $\mathrm{CHN}-\mathrm{GZ}+\mathrm{CHN}-\mathrm{XF}$ & Japan-H & CHN-WH & $\begin{array}{l}\text { AAC- } \\
\text { HQ }\end{array}$ & Argentina \\
\hline
\end{tabular}




\begin{tabular}{|c|l|l|l|l|l|l|l|}
\hline 6 & CHN-HN & $\begin{array}{l}\text { Japan-H + CHN- } \\
\text { LZ }\end{array}$ & Malaysia + CHN-XF & Japan-H & CHN-XF & $\begin{array}{l}\text { AAC- } \\
\text { HQ }\end{array}$ & India \\
\hline 7 & CHN-DB & $\begin{array}{l}\text { Japan-H+CHN- } \\
\text { SY }\end{array}$ & CHN-GZ + Singapore & Japan-H & CHN-WH & $\begin{array}{l}\text { AAC- } \\
\text { HQ }\end{array}$ & Pakistan \\
\hline 8 & CHN-HB & $\begin{array}{l}\text { Japan-H +CHN- } \\
\text { XF }\end{array}$ & Malaysia +Singapore & Japan-H & CHN-XF & $\begin{array}{l}\text { AAC- } \\
\text { HQ }\end{array}$ & Thailand \\
\hline 9 & $\begin{array}{l}\text { CHN-HN } \\
\text { LZan-H + CHN- }\end{array}$ & CHN-GZ + Singapore & Japan-H & CHN-WH & $\begin{array}{l}\text { AAC- } \\
\text { HQ }\end{array}$ & Brazil \\
\hline 10 & CHN-HB & $\begin{array}{l}\text { Japan-H+CHN- } \\
\text { SY }\end{array}$ & Malaysia +Singapore & Japan-H & CHN-XF & $\begin{array}{l}\text { AAC- } \\
\text { HQ }\end{array}$ & Argentina \\
\hline
\end{tabular}

Table 4 Dependency and co-ordination requirements for the eight configurations

\begin{tabular}{|c|c|c|c|}
\hline Configuration & Type 1 dependency and co-ordination requirements & $\begin{array}{l}\text { Type } 2 \text { dependency and co- } \\
\text { ordination requirements }\end{array}$ & $\begin{array}{l}\text { Level of } \\
\text { complexity }\end{array}$ \\
\hline 1 & $\begin{array}{l}\text { Dependencies exist between supply, manufacturing and } \\
\text { distribution; Notification needs to be issued by IDSS } \\
\text { when an activity is completed in upstream of the } \\
\text { manufacturing network. Manufacturing strategies are } \\
\text { dominantly represented by the Japanese Pull systems } \\
\text { and Chinese Push systems. }\end{array}$ & $\begin{array}{l}\text { All in Asia, and in the north semi- } \\
\text { sphere; No big time difference, } \\
\text { No seasonal difference; } \\
\text { transportation system relatively } \\
\text { reliable }\end{array}$ & $\begin{array}{lll}1 & \\
\end{array}$ \\
\hline 2 & $\begin{array}{l}\text { Dependencies exist between supply, manufacturing and } \\
\text { distribution; Notification needs to be issued by IDSS } \\
\text { when an activity is completed in upstream of the } \\
\text { manufacturing network. Most manufacturing activities } \\
\text { are positioned around central china. }\end{array}$ & $\begin{array}{l}\text { All in Asia, small time difference; } \\
\text { Transportation links between } \\
\text { China and Pakistan and between } \\
\text { China and Malaysia is convenient } \\
\text { and reliable. }\end{array}$ & 1.8 \\
\hline 4 & $\begin{array}{l}\text { Dependencies exist between supply, manufacturing and } \\
\text { distribution; Notification needs to be issued by IDSS } \\
\text { when an activity is completed in upstream of the } \\
\text { manufacturing network. Most manufacturing activities } \\
\text { spread across four countries (China, Japan, Malaysia } \\
\text { and Singapore) as well as across central and northern } \\
\text { China. }\end{array}$ & $\begin{array}{l}\text { Across Asia and America } \\
\text { (Brazil); Time zone difference, } \\
\text { seasonal difference; possible } \\
\text { delay with sea shipping. }\end{array}$ & 3.6 \\
\hline 5 & $\begin{array}{l}\text { Dependencies exist between supply, manufacturing and } \\
\text { distribution; Notification needs to be issued by IDSS } \\
\text { when an activity is completed in upstream of the } \\
\text { manufacturing network. Manufacturing activities spread } \\
\text { across China (central and north) and Japan. }\end{array}$ & $\begin{array}{l}\text { Across Asia and America } \\
\text { (Argentina); Big time zone } \\
\text { difference, big season difference; } \\
\text { possible delay with sea shipping }\end{array}$ & 3.8 \\
\hline 6 & $\begin{array}{l}\text { Dependencies exist between supply, manufacturing and } \\
\text { distribution; Notification needs to be issued by IDSS } \\
\text { when an activity is completed in upstream of the } \\
\text { manufacturing network. Manufacturing activities spread } \\
\text { across China (central only), Japan and Malaysia. }\end{array}$ & $\begin{array}{l}\text { All in Asia, small time difference; } \\
\text { Transportation links between } \\
\text { China and India and between } \\
\text { China and Malaysia is convenient } \\
\text { and reliable. }\end{array}$ & 2.4 \\
\hline 8 & $\begin{array}{l}\text { Dependencies exist between supply, manufacturing and } \\
\text { distribution; Notification needs to be issued by IDSS } \\
\text { when an activity is completed in upstream of the } \\
\text { manufacturing network. Most manufacturing activities } \\
\text { spread across four countries (China, Japan, Malaysia } \\
\text { and Singapore) as well as across central and northern } \\
\text { China. }\end{array}$ & $\begin{array}{l}\text { All in Asian, but the four } \\
\text { countries involved are across both } \\
\text { north semi-sphere and tropical } \\
\text { zone; time difference is small, but } \\
\text { with seasonal difference; } \\
\text { Transportation system relatively } \\
\text { reliable }\end{array}$ & 2.2 \\
\hline 9 & $\begin{array}{l}\text { Dependencies exist between supply, manufacturing and } \\
\text { distribution; Notification needs to be issued by IDSS } \\
\text { when an activity is completed in upstream of the } \\
\text { manufacturing network. Manufacturing activities spread } \\
\text { across China (central and south), Japan and Singapore. }\end{array}$ & $\begin{array}{l}\text { Across Asia and America } \\
\text { (Brazil); Time zone difference, } \\
\text { season difference, possible delay } \\
\text { with sea shipping }\end{array}$ & 3.8 \\
\hline 10 & $\begin{array}{l}\text { Dependencies exist between supply, manufacturing and } \\
\text { distribution; Notification needs to be issued by IDSS } \\
\text { when an activity is completed in upstream of the } \\
\text { manufacturing network. Most manufacturing activities } \\
\text { spread across four countries (China, Japan, Malaysia } \\
\text { and Singapore) as well as across central and northern } \\
\text { China. }\end{array}$ & $\begin{array}{l}\text { Across Asia and America } \\
\text { Argentina); big time zone } \\
\text { difference, season difference; } \\
\text { possible delay with sea shipping }\end{array}$ & 4.0 \\
\hline
\end{tabular}

